\title{
De novo Hepatocellular Carcinoma after Liver Transplantation
}

\author{
Sammy Saab*1,2, Kali Zhou ${ }^{1}$, Edward K Chang ${ }^{1}$ and Ronald W Busuttil ${ }^{2}$ \\ ${ }^{1}$ Department of Medicine, David Geffen School of Medicine at UCLA, Los Angeles, CA, USA; ${ }^{2}$ Department of Surgery, David Geffen \\ School of Medicine at UCLA, Los Angeles, CA, USA
}

\begin{abstract}
Liver transplantation is the definitive therapy for patients with advanced liver disease and its complications. Patients who are transplanted with a diagnosis of hepatocellular carcinoma (HCC) are at risk of recurrent cancer, and these patients are monitored on a regular basis for recurrence. In contrast, de novo $\mathrm{HCC}$ following liver transplantation is a very rare complication, and recipients without HCC at the time of transplantation are not screened. We describe the clinical features of de novo HCC over a decade after achieving a sustained viral response with treatment of hepatitis $\mathrm{C}$ and two decades after liver transplantation. Our case highlights the necessity of screening for $\mathrm{HCC}$ in the post-transplant patient with advanced liver disease even after viral clearance.

(C) 2015 The Second Affiliated Hospital of Chongqing Medical University. Published by XIA \& HE Publishing Ltd. All rights reserved.
\end{abstract}

\section{Introduction}

Hepatocellular carcinoma (HCC) is an important indication for liver transplantation. ${ }^{1}$ The risk of recurrent HCC depends on a number of factors, such as tumor burden, grade, and vascular invasion. Recipients transplanted for HCC are frequently surveyed for recurrent cancer. ${ }^{2,3}$ Liver transplant recipients are also screened for a number of de novo malignancies. ${ }^{4}$ De novo malignancies in liver transplant recipients are believed to be related to duration and intensity of immunosuppressive therapy. ${ }^{5}$ De novo HCC in liver transplant recipients and HCC recurrence after liver resection occur predominantly in the liver, whereas recurrent HCC occurs extra-hepatically. ${ }^{6}$ De novo HCC refers to the development of $\mathrm{HCC}$ in a liver transplant recipient without a history of HCC. ${ }^{7}$

De novo HCC is an uncommon complication in liver transplant recipients. ${ }^{8-15}$ Although screening guidelines exist for a variety of malignancies in liver transplant recipients, no recommendations exist for screening of de novo HCC. We report

Keywords: De novo hepatocellular carcinoma; Liver transplantation.

Abbreviations: AFP, alpha fetoprotein; HCC, hepatocellular carcinoma; HCV, hepatitis $C$ virus; MELD, model end-stage liver disease; MRCP, magnetic resonance cholangiopancreatography; OLT, orthotopic liver transplantation; UCLA, University of California, Los Angeles; UCSF, University of California, San Francisco; UK, United Kingdom.

Received: 08 October 2015; Revised: 27 October 2015; Accepted: 29 October 2015 DOI: $10.14218 /$ JCTH.2015.00033.

*Correspondence to: Sammy Saab, 200 Medical Plaza, Suite 214, Los Angeles, CA 90095, USA. Tel: +1-310-206-6705, Fax: +1-310-206-4197, E-mail: SSaab@mednet.ucla.edu a woman who developed de novo HCC over two decades after her initial liver transplantation.

\section{Case report}

The patient is a 47-year-old woman from Kuwait who underwent initial orthotopic liver transplantation (OLT) in the United Kingdom (UK) in 1989 for hepatitis C virus (HCV)-related cirrhosis. Post-OLT, she had a complicated medical course, including prolonged ventilatory failure with development of tracheoesophageal fistula and tracheal stenosis. She also required a colectomy and ileostomy for ulcerative colitis. Her course was also complicated by the need for multiple biliary tract dilatation and stent placement for biliary anastomotic strictures. She achieved a sustained viral response with interferon and ribavirin after a histological diagnosis was made of bridging fibrosis. She was followed regularly with laboratory tests. Because there was no evidence of malignancy on the explant, surveillance imaging was not performed.

While undergoing evaluation for ileostomy takedown, a magnetic resonance cholangiopancreatography (MRCP) in August 2008 revealed a $3 \mathrm{~cm}$ lesion in segment 1 of the liver, diagnosed as de novo HCC. Upon tissue diagnosis, the patient was treated with chemoembolization, radiofrequency ablation, and sorafenib in the UK. Despite treatment, her alpha fetoprotein (AFP) remained elevated at 1,180 ng/mL, and she was referred to University of California, Los Angeles (UCLA) for consideration of repeat OLT.

At UCLA, she was noted to be a thin woman with no stigmata of chronic liver disease. An ileostomy was present at the right lower quadrant. Computed tomography imaging of the abdomen revealed an ill-defined area of rounded enhancement measuring $4.7 \mathrm{~cm} \times 3.9 \mathrm{~cm}$ hypodense lesion, corroborated as a mildly hypervascular lesion on magnetic resonance imaging (Fig. 1). Pathology was consistent with a well to moderately differentiated HCC. The multidisciplinary hepatobiliary tumor board recommended chemoembolization for treatment of the HCC. The patient underwent another two rounds of chemoembolization in 2011 while listed for transplant. Whole body imaging confirmed no evidence of metastatic disease. She received a regional review board model end-stage liver disease (MELD) exception for meeting University of California, San Francisco (UCSF) criteria. ${ }^{16}$

The patient underwent another liver transplant in March of 2012. Three months prior to transplant, she had undergone magnetic resonance imaging that failed to show evidence of recurrent HCC, despite an AFP value greater than $1,000 \mathrm{ng} / \mathrm{mL}$. Systemic chemotherapy was not offered prior to her 
Saab S. et al: De novo hepatocellular carcinoma after liver transplantation

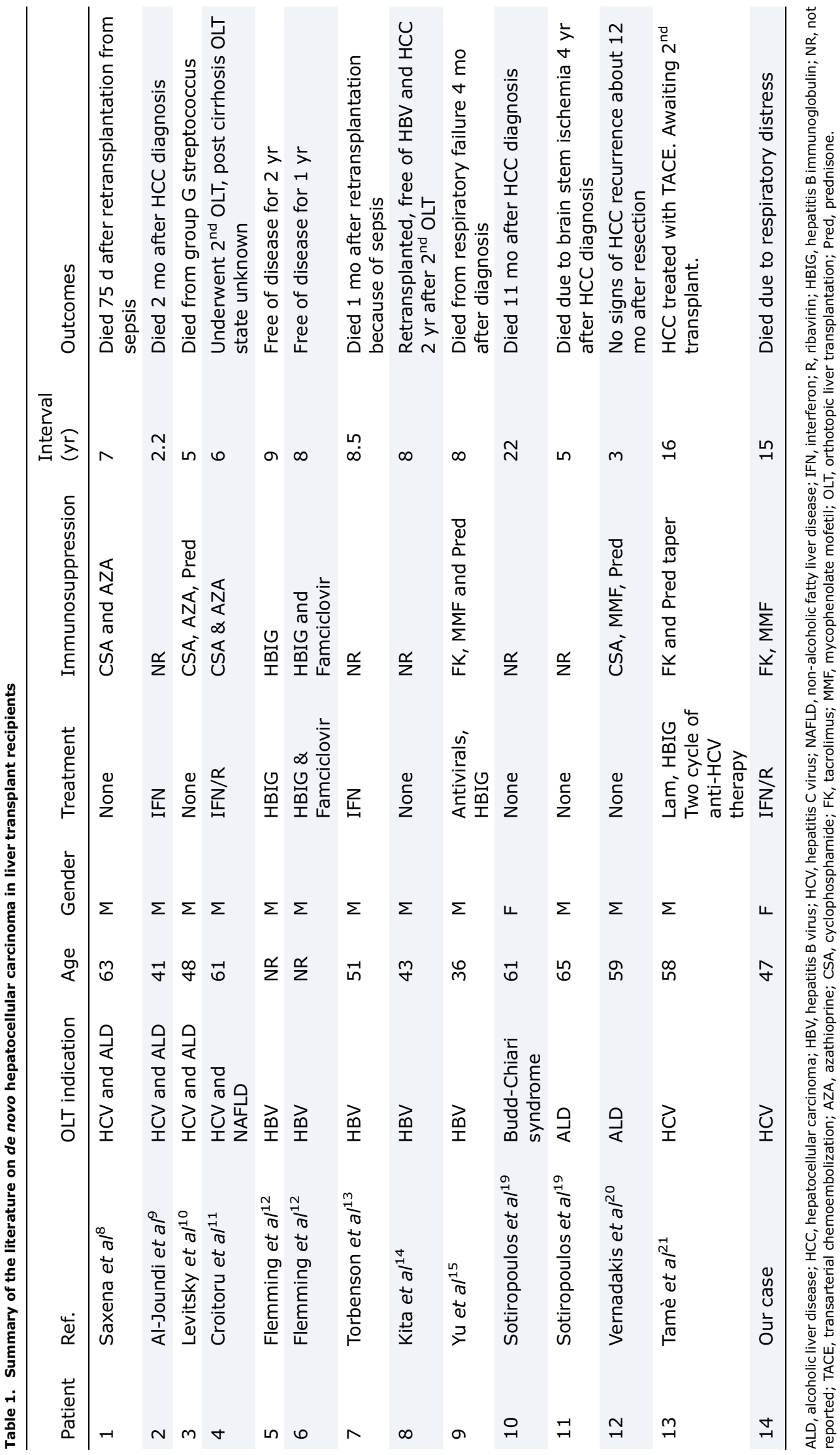




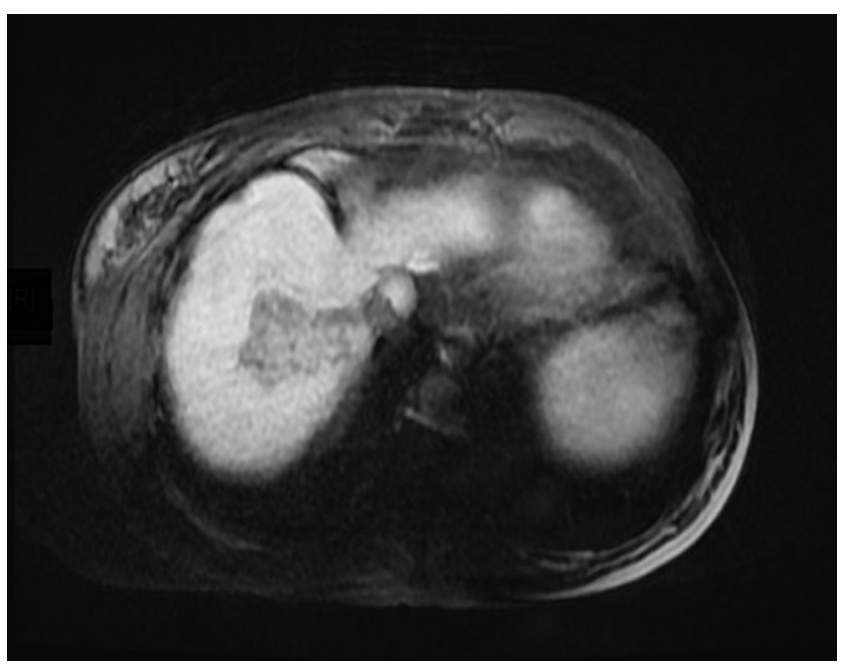

Fig. 1. Hypervascular hepatic mass measuring $4.7 \mathrm{~cm} \times 3.9 \mathrm{~cm}$.

second transplant because there was radiological evidence of tumor.

Findings on explanted liver included a grade 2/4 HCC measuring $6.1 \mathrm{~cm}$ in maximal diameter, small and large vessel lymphovascular tumor invasion, and cirrhosis. After transplant, the AFP level decreased to $54.6 \mathrm{ng} / \mathrm{mL}$. On routine chest imaging 9 mo after transplant, a new right lower lobe pleural lesion was noted. Biopsy of one lesion was consistent with recurrent metastatic $\mathrm{HCC}$.

Despite the use of sirolimus, sorafenib, gemcitabine, oxaliplatin, and capecitabine, there was progression of metastatic disease with additional involvement of the skull and dura. The patient expired of respiratory distress in August of 2014.

\section{Discussion}

Recommendations exist for the screening of new HCC in the general population and for de novo cutaneous malignancies in liver transplant recipients. ${ }^{4,17}$ De novo HCC is an infrequent complication in liver transplant recipients. ${ }^{18}$ Most cases of de novo $\mathrm{HCC}$ in liver transplant recipients have occurred in men and in the setting of viral hepatitis B or C. However, Budd-Chiari and alcohol liver disease alone have also been associated with de novo HCC (Table 1). ${ }^{19,20}$ The time interval between liver transplant and diagnosis of de novo HCC ranges between 2 and 22 years. The interval between transplant and diagnosis of de novo HCC in this case is one of the longest intervals to be reported.

In our review of published cases (including ours), three patients were found to have de novo HCC at the time of a second transplant (Table 1). ${ }^{8,11,13}$ Of the 13 cases, two were multifocal and in the other 11 cases the mean diameter was $3.2 \mathrm{~cm}$ with a range between 0.7 to $7.3 \mathrm{~cm} .{ }^{8,10,12-14}$ No treatment was rendered to four patients, $9,10,19,20$ one underwent radiofrequency ablation, ${ }^{13}$ two had surgical resection, ${ }^{13}$ and three had transarterial chemoembolization (including our patient). ${ }^{14,19,21}$ Two cases of HCC have been described in recipients with a history of $\mathrm{HCC}$ in the explants, but evidence of a HCC in the new graft with cells likely originating from the donor. 22,23

Our case report highlights that despite achieving a sustained viral response, liver transplant recipients may remain at risk of HCC if cirrhosis has developed. Indeed, achieving a sustained viral response may reduce the risk of HCC but does not necessarily eliminate it. ${ }^{24}$

Differentiating between de novo and recurrent HCC is important, particularly when considering retransplantation, since recurrent $\mathrm{HCC}$ is more likely to be associated with metastatic disease. Retransplanting patients for recurrent HCC is contraindicated because of poor survival. ${ }^{25-27}$ Our patient did not have $\mathrm{HCC}$ at the time of her first transplantation. All previous cases describing de novo HCC occurring in the setting of HCV noted a concomitant cause of liver disease from alcohol or fatty liver. Our patient was neither overweight or had a history of alcohol use. Another possibility is that the tumor arose for from the donor. We do not believe this is likely in our patient, given the long duration between transplantation and diagnosis of de novo HCC (approximately two decades). HCC described in two cases occurred less than 7 years from transplant. 22,23

\section{Conclusions}

The review of prior cases also highlights the need for effective therapy for HCC in liver transplant recipients. Patients were treated with a variety of modalities, including systemic therapy, resection, locoregional therapy, and retransplantation. Treatment efficacy is limited for a majority of patients, including our patient, who had expired at the time of case report publication.

\section{Conflict of interest}

None.

\section{Author contributions}

Designing the research study (SS, KZ), collecting the data (KZ, EKC), writing the manuscript (SS, KZ), critically reviewing and revising the manuscript (SS, KZ, EKC, RWB).

\section{References}

[1] Pomfret EA, Washburn K, Wald C, Nalesnik MA, Douglas D, Russo M, et al. Report of a national conference on liver allocation in patients with hepatocellular carcinoma in the United States. Liver Transpl 2010;16:262-278. doi: $10.1002 /$ It. 21999.

[2] Saab S, Manne V, Bui V, Sundaram V. Cumulative radiation exposure in liver transplant candidates and patients transplanted with hepatocellular carcinoma. J Liver: Dis Transplant 2015; in press.

[3] Ladabaum U, Cheng SL, Yao FY, Roberts JP. Cost-effectiveness of screening for recurrent hepatocellular carcinoma after liver transplantation. Clin Transplant 2011;25:283-291. doi: 10.1111/j.1399-0012.2010.01212.

[4] McGuire BM, Rosenthal P, Brown CC, Busch AM, Calcatera SM, Claria RS, et al. Long-term management of the liver transplant patient: recommendations for the primary care doctor. Am J Transplant 2009;9:1988-2003. doi: 10.1111/j. 1600-6143.2009.02733.

[5] Haagsma EB, Hagens VE, Schaapveld M, van den Berg AP, de Vries EG, Klompmaker IJ, et al. Increased cancer risk after liver transplantation: a population-based study. J Hepatol 2001;34:84-91. doi: 10.1016/S01688278(00)00077-5.

[6] Hatzaras I, Bischof DA, Fahy B, Cosgrove D, Pawlik TM. Treatment options and surveillance strategies after therapy for hepatocellular carcinoma. Ann Surg Oncol 2014;21:758-766. doi: 10.1245/s10434-013-3254-5.

[7] Bhoori S, Mazzafero V. Current challenges in liver transplantation for hepatocellular carcinoma. Best Pract Res Clin Gastroenterol 2014;28:867-879. doi: 10.1016/j.bpg.2014.08.001.

[8] Saxena R, Ye MQ, Emre S, Klion F, Nalesnik MA, Thung SN. De novo hepatocellular carcinoma in a hepatic allograft with recurrent hepatitis $C$ cirrhosis. Liver Transpl Surg 1999;5:81-82. doi: 10.1002/It.500050111. 
Saab S. et al: De novo hepatocellular carcinoma after liver transplantation

[9] Al-Joundi T, Gibson S, Brunt EM, Shakil O, Lee RS, Di Bisceglie AM. Delayed recurrence of hepatocellular carcinoma after liver transplantation: detection of origin by chromosomal analysis. Liver Transpl 2000;6:374-375. doi: 10. $1053 /$ Iv.2000.5202.

[10] Levitsky J, Faust TW, Cohen SM, Te HS. Group G streptococcal bacteremia and de novo hepatocellular carcinoma after liver transplantation. Liver Transpl 2002;8:572. doi: 10.1053/jlts.2002.33275.

[11] Croitoru A, Schiano TD, Schwartz M, Roayaie S, Xu R, Suriawinata A, et al. De novo hepatocellular carcinoma occurring in a transplanted liver: case report and review of the literature. Dig Dis Sci 2006;51:1780-1782. doi: 10.1007/s10620-006-9333-8.

[12] Flemming $\mathrm{P}$, Tillmann $\mathrm{HL}$, Barg-Hock $\mathrm{H}$, Kleeberger W, Manns MP, Klempnauer J, et al. Donor origin of de novo hepatocellular carcinoma in hepatic allografts. Transplantation 2003;76:1625-1627. doi: 10.1097/01.TP. 00000 86341.57778.D9.

[13] Torbenson M, Grover D, Boitnott J, Klein A, Molmenti E. De novo hepatocellular carcinoma in a liver allograft associated with recurrent hepatitis B. Transplant Proc 2005;37:2205-2206. doi: 10.1016/j.transproceed.2005. 03.093.

[14] Kita Y, Klintmalm G, Kobayashi S, Yanaga K. Retransplantation for de novo hepatocellular carcinoma in a liver allograft with recurrent hepatitis B cirrhosis 14 years after primary liver transplantation. Dig Dis Sci 2007;52: 3392-3393. doi: 10.1007/s10620-006-9574-6.

[15] Yu S, Guo H, Zhuang L, Yu J, Yan S, Zhang M, et al. A case report of de novo hepatocellular carcinoma after living donor liver transplantation. World J Surg Oncol 2013;11:176. doi: 10.1186/1477-7819-11-176.

[16] Yao FY, Xiao L, Bass NM, Kerlan R, Ascher NL, Roberts JP. Liver transplantation for hepatocellular carcinoma: validation of the UCSF-expanded criteria based on preoperative imaging. Am J Transplant 2007;7:2587-2596. doi: 10.1111/j.1600-6143.2007.01965.x.

[17] Singh S, Watt KD. Long-term medical management of the liver transplant recipient: what the primary care physician needs to know. Mayo Clin Proc 2012;87:779-790. doi: 10.1016/j.mayocp.2012.02.021.

[18] Trevisani F, Garuti F, Cucchetti A, Lenzi B, Bernardi M. De Novo hepatocellular carcinoma of liver allograft: a neglected issue. Cancer Lett 2015;356:47-54. doi: 10.1016/j.canlet.2014.11.032.
[19] Sotiropoulos GC, Frilling A, Molmenti EP, Brokalaki EI, Beckebaum S, Omar OS, et al. De novo hepatocellular carcinoma in recurrent liver cirrhosis after liver transplantation for benign hepatic disease: is a deceased donor re-transplantation justified? Transplantation 2006;82:1112. doi: 10.1097/ 01.tp.0000230283.84633.4a.

[20] Vernadakis S, Poetsch M, Weber F, Treckmann J, Mathe Z, Baba HA, et al. Donor origin de novo HCC in a noncirrhotic liver allograft 3 years after liver transplantation. Transpl Int 2010;23:341-343. doi: 10.1111/j.1432-2277. 2009.00942.

[21] Tamè M, Calvanese C, Cucchetti A, Gruppioni E, Colecchia A, Bazzoli F. The Onset of de novo Hepatocellular Carcinoma after Liver Transplantation can be both of Donor and Recipient Origin. A Case Report. J Gastrointestin Liver Dis 2015;24:387-389. doi: 10.15403/jgld.2014.1121.243.gpp.

[22] Morita K, Taketomi A, Soejima Y, Ikegami T, Fukuhara T, Iguchi T, et al. De novo hepatocellular carcinoma in a liver graft with sustained hepatitis $C$ virus clearance after living donor liver transplantation. Liver Transpl 2009; 15:1412-1416. doi: 10.1002/It.21894.

[23] Strautnieks S, Thompson RJ, Amarapurkar A. De novo hepatocellularcarcinoma in allograft liver with background of hepatitis $C$ virus infection, cirrhosis and previous genetically distinct HCC in native liver [AASDL abstract 1874]. Hepatology 2001;4:640A.

[24] Morgan RL, Baack B, Smith BD, Yartel A, Pitasi M, Falck-Ytter Y. Eradication of hepatitis $C$ virus infection and the development of hepatocellular carcinoma: a meta-analysis of observational studies. Ann Intern Med 2013;158: 329-337. doi: 10.7326/0003-4819-158-5-201303050-00005.

[25] Zimmerman MA, Ghobrial RM, Tong MJ, Hiatt JR, Cameron AM, Hong J, et al. Recurrence of hepatocellular carcinoma following liver transplantation: a review of preoperative and post operative prognostic indicators. Arch Surg 2008;143:182-188. doi: 10.1001/archsurg.2007.39.

[26] Clavien PA, Lesurtel M, Bossuyt PM, Gores GJ, Langer B, Perrier A. Recommendations for liver transplantation for hepatocellular carcinoma: an international consensus conference report. Lancet Oncol 2012;13:e11-e22. doi: 10.1016/S1470-2045(11)70175-9.

[27] Hollebecque A, Decaens T, Boleslawski E, Mathurin P, Duvoux C, Pruvot FR, et al. Natural history and therapeutic management of recurrent hepatocellular carcinoma after liver transplantation. Gastroenterol Clin Biol 2009;33: 361-369. doi: 10.1016/j.gcb.2009.02.036. 